\title{
Multi-instrumental Investigation of the Effect of Cadmium(II) and Lead(II) Ions on Early Somatic Spruce Embryos
}

\author{
Veronika Supalkova ${ }^{1,2}$, Jiri Petrek ${ }^{1}$, Jiri Baloun ${ }^{1,2}$, Vojtech Adam ${ }^{1,3}$, Karel Bartusek ${ }^{4}$, Libuse \\ Trnkova $^{5}$, Miroslava Beklova ${ }^{6}$, Vaclav Diopan ${ }^{1,2}$, Ladislav Havel ${ }^{1}$ and Rene Kizek ${ }^{2, *}$ \\ ${ }^{1}$ Department of Plant Biology, ${ }^{2}$ Department of Chemistry and Biochemistry, and ${ }^{3}$ Department of \\ Animal Nutrition and Forage Production, Faculty of Agronomy, Mendel University of Agriculture \\ and Forestry, Zemedelska 1, CZ-613 00 Brno, Czech Republic \\ ${ }^{4}$ Institute of Scientific Instruments, Academy of Sciences of the Czech Republic, Kralovopolska 147, \\ CZ-612 00 Brno, Czech Republic \\ ${ }^{5}$ Department of Chemistry, Faculty of Science, Masaryk University, Kotlarska 2, CZ-611 37 Brno, \\ Czech Republic \\ ${ }^{6}$ Department of Veterinary Ecology and Environmental Protection, Faculty of Veterinary Hygiene and \\ Ecology, University of Veterinary and Pharmaceutical Sciences, Palackeho 1-3, CZ-612 42 Brno, \\ Czech Republic
}

* Author to whom correspondence should be addressed; E-mail: kizek@sci.muni.cz

Received: 5 May 2007 / Accepted: 23 May 2007 / Published: 31 May 2007

\begin{abstract}
The main aim of this work was to use multi-instrumental analytical apparatus to investigate the effects of treatment with cadmium(II) and/or lead(II) ions (50, 250 and 500 $\mu \mathrm{M}$ ) for twelve days on early somatic spruce embryos (ESEs). Primarily we used image analysis for estimation of growth and a fluorimetric sensor for enzymatic detection of viability of the treated ESEs. It follows from the obtained results that Cd caused higher toxicity to ESEs than $\mathrm{Pb}$. Besides this fundamental finding, we observed that ESEs grew and developed better in the presence of $500 \mu \mathrm{M}$ of the metal ions than in the presence of $250 \mu \mathrm{M}$. Based on the results obtained using nuclear magnetic resonance this phenomenon was related to an increase of the area of ESE clusters by intensive uptake of water from the cultivation medium, due to dilution of the heavy metal concentration inside the cluster. In addition we studied the glutathione content in treated ESEs by the adsorptive transfer stripping technique coupled with the differential pulse voltammetry Brdicka reaction. GSH contents increased up to $148 \mathrm{ng} / \mathrm{mg}$ (clone 2/32) and $158 \mathrm{ng} / \mathrm{mg}$ (clone PE 14) after twelve
\end{abstract}


day long treatment with Cd-EDTA ions. The GSH content was about 150 and $160 \%$ higher in comparison with the ESEs treated with Pb-EDTA ions, respectively. The difference between GSH contents determined in ESEs treated with Pb-EDTA and Cd-EDTA ions correlates with the higher toxicity of cadmium(II) ions.

Keywords: Early somatic Spruce embryos; Glutathione; Heavy metals; Plant cells; Esterase activity; Fluorescence detection.

\section{Introduction}

Plants are continuously exposed to abiotic and biotic stresses in their environment. Their growth and development are closely associated with their ability to respond and adapt to external stresses. Plants respond to pathogen attack and/or external stresses by marked changes in gene expression, resulting in the de novo syntheses of specific peptides and proteins such as glutathione and/or phytochelatins [1-3]. Glutathione (GSH) is considered to be an essential constituent of all living cells and is the most abundant intracellular non-protein thiol [4]. It plays an important role in the detoxification of toxic heavy metals and scavenging of reactive oxygen species. Moreover, the structure of GSH (a tripeptide with the sequence $\gamma$-Glu-Cys-Gly) is strongly related to that of the phytochelatins (PCs) [5], because PCs could be synthesised from GSH. PCs, small peptides consisting of 4-23 amino acids, participate in the detoxification of heavy metals because they have the ability to transport heavy metal ions to vacuoles [1], where immediate toxicity is no longer threatening. PCs have a basic formula ( $\gamma$-Glu-Cys)n-Gly ( $n=2$ to 11 ) and form M-PC complexes with the heavy metals (M), in which the metal is bound via the cysteine unit SH group [1,6,7]. A very wide range of analytical techniques, including both chromatographic coupled with different detectors and stationary ones, such as electrochemical methods, have been utilized for determination of thiols in samples of interest [8-24].

Besides determination of expression of peptides and proteins in plants and their cell cultures during treatment with heavy metals, studies of the growth and viability of biological models of interest under these stresses are need. The most frequently used methods for estimation of the growth of the cell cultures are based on the counting and/or weighing of cells or tissues [25]. The disadvantages of these methods are the destruction and/or contamination of cultures during the analysis. Based on a recently published paper it appears that image analysis could offer a more insightful tool for studying cell growth without any damage and contamination of the biological material of interest [26-30]. Besides estimation of growth, the most commonly used technique for studying cell viability is double staining with propidium iodide and fluorescein diacetate [31]. Recently we have reported that the determination of activity of plant esterases could be used as a marker, not only of cell growth and viability, but also of slight differences in cell metabolism under various conditions [31-34]. Because of the advantages and disadvantages of the techniques mentioned, their combination can be very promising to investigate the effects on plant cells by heavy metals from different point of view. Thus, the main aim of our work was to utilize multi-instrumental analytical apparatus to investigate the how early somatic Spruce embryos (ESEs) were affected by treatment with heavy metals (cadmium(II) and lead(II) ions) for twelve days. 


\section{Materials and Methods}

\subsection{Chemicals}

Fluorescein diacetate (FDA) and all other reagents used (ACS purity) were purchased from Sigma Aldrich Chemical Corp. (USA), unless noted otherwise. Celulysin was purchased from Calbiochem (USA). All solutions were prepared using deionised water (18.2 M $\Omega$, Iwa 20, Watek, Czech Republic). If not otherwise indicated, culture media were prepared using plant cell culture chemicals purchased from Duchefa Biochemie BV (Haarlem, The Netherlands).

\subsection{Plant material and cultivation conditions}

ESE clones of the Norway spruce (Picea abies /L./ Karst.) designated as 2/32, and clones of blue spruce (Picea pungens Engelm.) designated as PE 14 were used in our experiments. The cultures were maintained on a semisolid half-strength LP medium (Gelrite Gellan Gum, Merck, Germany) [35] with modifications [36]. The concentrations of 2,4-dichlorofenoxyacetic acid and N6-benzyladenine were 4.4 and $9 \mu \mathrm{M}$, respectively [37]. The $\mathrm{pH}$ value was adjusted to 5.7-5.8 before autoclaving $\left(121^{\circ} \mathrm{C}\right.$, $100 \mathrm{kPa}, 20 \mathrm{~min}$ ). The organic part of the medium, excluding saccharose, was sterilized by filtration through a $0.2 \mu \mathrm{m}$ polyethylensulfone membrane (Whatman, Puradisc 25 AS). Sub-cultivation of stock cultures was carried out at 2-week intervals. The stock and experimental cultures were maintained in a cultivation box in the dark at a temperature of $23 \pm 2{ }^{\circ} \mathrm{C}$. Cultivation medium was modified with an addition of lead chelate (Pb-EDTA) and/or cadmium chelate (Cd-EDTA) at 50, 250 and $500 \mu \mathrm{M}$. A stock solution of $\mathrm{Pb}$-EDTA (Cd-EDTA) was prepared by mixing $\mathrm{Pb}\left(\mathrm{NO}_{3}\right)_{2}$ or $\left(\mathrm{Cd}\left(\mathrm{NO}_{3}\right)_{2}\right)$ with ethylenediaminetetraacetic acid (EDTA) in a 1:1 molar ratio and stirred at $50^{\circ} \mathrm{C}$ for $1 \mathrm{~h}$. The filtersterilized Pb-EDTA and/or Cd-EDTA complex was added to the autoclaved culture medium.

\subsection{Computer image analysis}

We used a charge-coupled device (CCD) camera for observation of growth of spruce ESE cultures. The images of ESE clusters were recorded at the beginning of the cultivation and in certain intervals according to the duraction of the cultivation. The data were converted to digital images with the GrabIT (version 1.3) program. The area size of ESEs clusters in digital images was calculated by program Image-Pro Plus, (Sony, ver. 1.3). The data were processed in Excel (Microsoft). Other details were published in Ref. No. [30].

\subsection{Bright field photography of ESEs}

ESEs (about $0.1 \mathrm{mg}$ ) were harvested using a scalpel and transferred onto a microscope slide. The ESEs was spread and covered with a glass. Then, the sample was placed to microscope (Olympus AX 70 , Japan). The images were magnified forty times by an Olympus 4040 digital camera and converted to digital images with the Grab-IT (version 1.3) program. 


\subsection{Double staining}

Modified double staining with fluorescein diacetate (FDA) and propidium iodide (PI) for the determination of the viability of ESEs was used. FDA causes green fluorescence in viable cells because the non-fluorescent FDA easily penetrates into viable cells where it is hydrolyzed to a brightly fluorescent fluorescein $\left(\lambda_{\text {excit }}=490 \mathrm{~nm}\right.$ and $\left.\lambda_{\text {emis }}=514 \mathrm{~nm}\right)$ that does not diffuse out readily through the cytoplasmatic membrane. The red fluorescence of PI $\left(\lambda_{\text {excit }}=536 \mathrm{~nm}\right.$ and $\left.\lambda_{\text {emis }}=620 \mathrm{~nm}\right)$ in cells shows that these cells are dead because this compound cannot pass through the functional cytoplasmatic membrane. In our experiments ESEs ( 1 mg) were harvested and diluted with water to a final volume of $50 \mu \mathrm{L}$. Stock solutions of PI and FDA were added to a final concentration of $20 \mu \mathrm{g} / \mathrm{mL}$ and $1 \mu \mathrm{g} / \mathrm{mL}$, respectively. After $5 \mathrm{~min}$ of incubation at room temperature, the percentage of dead and viable cells was evaluated using an Olympus AX 70 fluorescence microscope with an Olympus cube U-MWU coupled with the digital camera. The percentage quantification of red (dead) and green (viable) areas in compact embryonic groups of single embryos was determined in an acquired digital picture by an IA method (the Sony Image-Pro Plus program, ver. 1.3, was used).

\subsection{Intracellular esterases assay - Fluorimetric sensor}

The harvested ESEs (100-200 mg) were mixed with extraction buffer ( $\left.250 \mathrm{mM} \mathrm{K}_{3} \mathrm{PO}_{4}, \mathrm{pH} 8.7\right)$ to a final volume of $1 \mathrm{~mL}$ and homogenised using a glassy Potter-Elvehjem homogenizer (Kavalier, Czech Republic) and/or hand-operated homogenizer ULTRA-TURRAX T8 (IKA, Germany) placed in an ice bath for $10 \mathrm{~min}$ (for details see the Results and Discussion section). The redox state of the obtained solution was maintained by addition of dithiothreitol (DTT) at a concentration of $1 \mathrm{mM}$. The homogenised samples were sonicated for $1 \mathrm{~min}$ in an ice bath using a Transsonic T310 sonicator (Czech Republic). The homogenate was centrifuged at $10,000 \mathrm{~g}$ for $15 \mathrm{~min}$ and at $4{ }^{\circ} \mathrm{C}$ (MR 22 centrifuge, Jouan, USA). An aliquot of the supernatant (5-20 $\mu \mathrm{L})$ was mixed with $1 \mathrm{M} \mathrm{K}_{3} \mathrm{PO}_{4}$ buffer ( $\mathrm{pH}$ 8.7) and analysed using a fluorimetric sensor as published by Vitecek et al. [38]. Briefly, the enzymatic reaction was started by the addition of FDA to a final concentration of $5 \mu \mathrm{M}$ and the final volume of the reaction mixture was $1 \mathrm{~mL}$. An equal volume of extraction buffer was used as a blank. After incubation for $15 \mathrm{~min}$ at $45{ }^{\circ} \mathrm{C}$ (the temperature was controlled in a dry block, Major Science, Taiwan), an aliquot $(5-20 \mu \mathrm{L})$ of the reaction mixture was added to $250 \mathrm{mM}$ potassium $\mathrm{K}_{3} \mathrm{PO}_{4}(\mathrm{pH}$ $\left.8.7,1980-1995 \mu \mathrm{L}, 25^{\circ} \mathrm{C}\right)$ in a commonly used plastic cuvette $(1 \mathrm{~cm})$. The fluorescence $\left(\lambda_{\text {excit }} 490 \mathrm{~nm}\right.$ and $\lambda_{\text {emis }} 514 \mathrm{~nm}$ ) was read immediately using a spectrofluorimetric detector (RF-551, Shimadzu, USA). A stock solution of FDA was prepared in acetone dried by anhydrous calcium chloride. The amount of acetone in the reaction mixture did not exceed $1 \%(\mathrm{v} / \mathrm{v})$. Esterase activity in international units (IU, one unit liberates one $\mu \mathrm{mol}$ of fluorescein per minute under specified conditions) was recalculated to relative units (100\% represents the highest activity measured in experiment).

\subsection{Electrochemical measurements}

Electrochemical measurements were performed with AUTOLAB Analyser (EcoChemie, Netherlands) connected to VA-Stand 663 (Metrohm, Switzerland), using a standard cell with three 
electrodes. The working electrode was a hanging mercury drop electrode (HMDE) with a drop area of $0.4 \mathrm{~mm}^{2}$. The reference electrode was an $\mathrm{Ag} / \mathrm{AgCl} / 3 \mathrm{M} \mathrm{KCl}$ electrode and the auxiliary electrode was a carbon electrode. For smoothing and baseline correction the software GPES 4.4 supplied by EcoChemie was employed. For the adsorptive transfer stripping technique (AdTS) used in connection with differential pulse voltammetry (DPV) Brdicka reaction the Brdicka supporting electrolyte containing $1 \mathrm{mM} \mathrm{Co}\left(\mathrm{NH}_{3}\right)_{6} \mathrm{Cl}_{3}$ and $1 \mathrm{M}$ ammonia buffer $\left(\mathrm{NH}_{3}(\mathrm{aq})+\mathrm{NH}_{4} \mathrm{Cl}, \mathrm{pH}=9.6\right)$ was used; surface-active agent was not added. AdTS DPV Brdicka reaction parameters were as follows: an initial potential of $-0.6 \mathrm{~V}$, an end potential $-1.6 \mathrm{~V}$, a modulation time $0.057 \mathrm{~s}$, a time interval $0.2 \mathrm{~s}$, a step potential of $1.05 \mathrm{mV} / \mathrm{s}$, a modulation amplitude of $250 \mathrm{mV}$, Eads $=0 \mathrm{~V}$. Temperature of supporting electrolyte was $4{ }^{\circ} \mathrm{C}[39]$.

\subsection{Nuclear magnetic resonance}

Experiments were performed on a home-built MR imaging system equipped with a $4.7 \mathrm{~T}$ horizontal-bore magnet with a bore diameter of $20 \mathrm{~cm}$, operating at $200 \mathrm{MHz}$ for ${ }^{1} \mathrm{H}$ [40-43]. Current active shielding gradient coils providing up to $180 \mathrm{mT} / \mathrm{m}$ gradient strength. Measuring samples were cultivated in plastic Petri dish (50 $\mathrm{mm}$ in diameter). The axial MRI images were acquired using a classic Spin Echo protocol with the following parameters: echo time $(\mathrm{TE})=13.5 \mathrm{~ms}$, relaxation delay $(\mathrm{TR})=3.8 \mathrm{~s}$, matrix size $=256 \times 256$ pixels $(30 \times 30 \mathrm{~mm}$ with resolution $0.117 \mathrm{~mm}$ per pixel $)$, slice thickness $=2 \mathrm{~mm}$ and number of averages $(\mathrm{NA})=5$. The MR signal was accumulated two times. The data were processed in Marevisi program.

\subsection{Statistical analysis}

Acquired data was processed in Excel (Microsoft) and analyzed by the QCExpert software (TriloBite, Statistical Software) using analysis of variance (ANOVA). Statistical significance of the differences between weight and area of clusters was determined, considering $\mathrm{P}<0.05$ as significant.

\section{Results and Discussion}

\subsection{Changes in morphology of somatic embryos under heavy metals stress}

Here, we studied the influence of cadmium and lead on growth, viability and content of thiol compounds (glutathione and phytochelatin) in Early Somatic Embryos (ESEs) of Norway spruce (Picea abies /L./ Karst.) clone 2/32 and Blue spruce (Picea pungens Engelm.) clone PE 14. The heavy metals were added to cultivation medium in form of EDTA chelates (Cd-EDTA and $\mathrm{Pb}$-EDTA), because if we used metals as salts (nitrates, sulphates, acetates), we observed precipitation [15]. Therefore, the concentration of free metal was dubious [44-46]. Pictures of the studied ESEs treated by lead and/or cadmium ions are shown in Figure 1. 
Figure 1. Pictures of ESEs ( $\mathrm{a}$ - embryonic group, $\mathrm{b}$ - embryonic tubes and $\mathrm{c}$ - embryonic suspensor) after twelve days of cultivation without heavy metal - control (A), with 500 $\mu \mathrm{M}$ Cd-EDTA (B) and with $500 \mu \mathrm{M}$ Pb-EDTA (C).

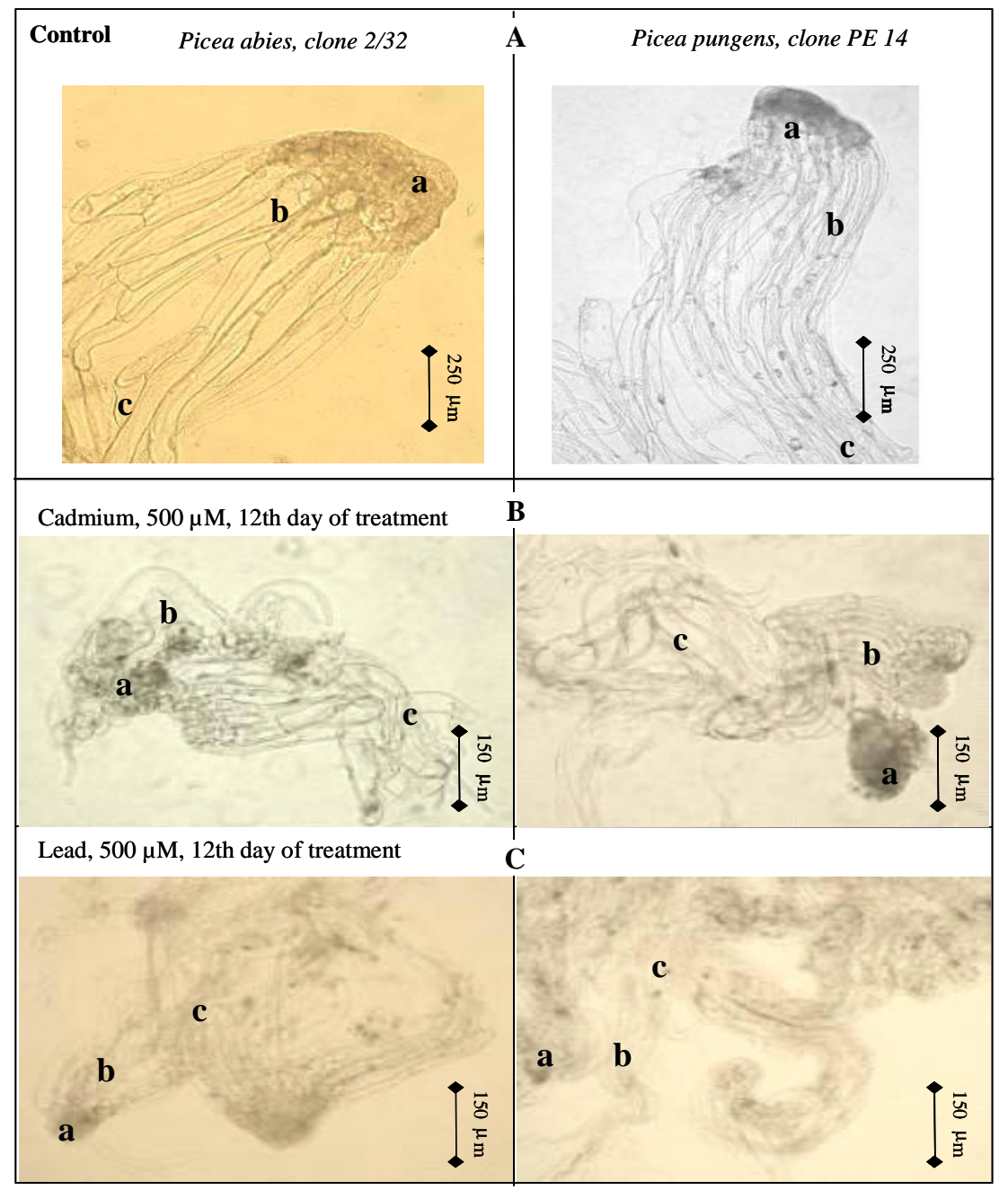

The images (bright field) were magnified forty times by the Olympus 4040 digital camera and converted to digital images in the Grab-IT (version 1.3) program.

We observed marked morphological differences in embryonic groups, tubes and suspensor cells between control ESEs and treated ones (Figure 1). In addition we also observed a decrease in viability of cells of the embryonic group in treated ESEs using double staining by FDA/PI. It clearly follows from the results obtained that cadmium and lead ions in the form of EDTA complexes are toxic for both clone 2/32 and PE 14 of ESEs.

\subsection{Determination of viability and growth of spruce embryos treated by heavy metals}

Recently we have published a paper where we used image analysis (IA) for determination of growth and viability of ESEs [30]. Therefore we utilized the image analysis for estimation of growth (increase in ESEs clusters area) and viability (quantification of red and green cells after FDA/PI double staining) of ESEs treated by lead and/or cadmium ions for twelve days (Figure 2). 
Figure 2. The influence of Pb-EDTA (A, B) and Cd-EDTA (C, D) on ESE growth of clones 2/32 and PE 14 after twelve days of cultivation.

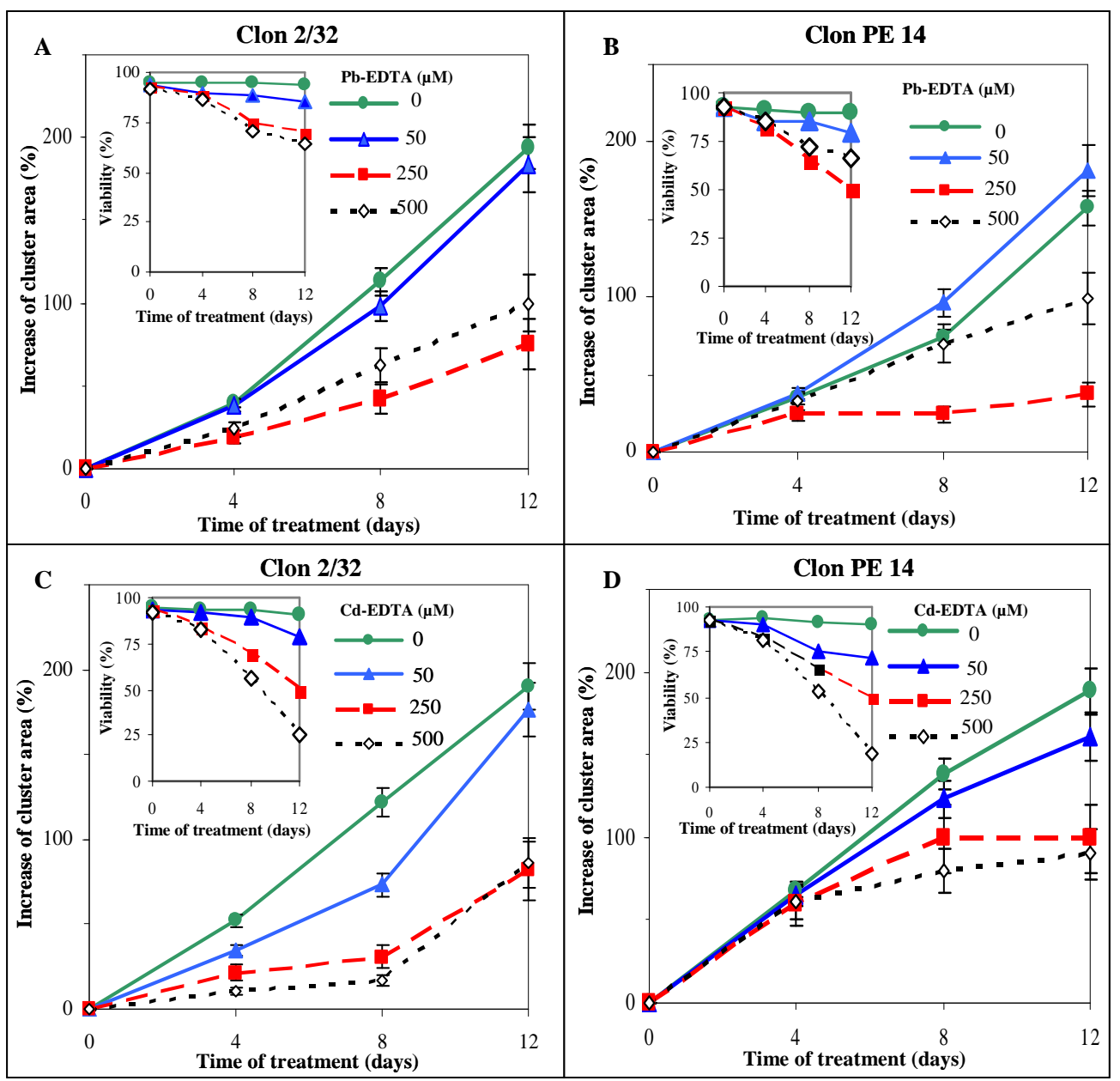

The $\mathrm{Cd}$ and/or $\mathrm{Pb}$ were added as Cd-EDTA and/or Pb-EDTA chelates $(0,50,250$ and $500 \mu \mathrm{M})$ to LP1/2 cultivation medium at the beginning of the experiment. The growth was determined by IA. For other details see the Material and Methods section and Petrek et al. [30]. Insets: Influence of Pb-EDTA and Cd-EDTA on viability of spruce embryos of clones 2/32 and PE 14 determined by double staining.

Growth of non-treated ESEs was proportional to the length of the cultivation for both the 2/32 and PE 14 clones. At the end of the experiment, their cluster areas increased more than $150-200 \%$ in comparison with the initial area. The lowest dose of Pb-EDTA $(50 \mu \mathrm{M})$ caused a growth depression of clone $2 / 32$ of about $5 \%$ in comparison with control (Figures $2 \mathrm{~A}, \mathrm{~B}$ ). On the other hand, this Pb-EDTA concentration stimulated the growth of clone PE 14 by more than $60 \%$ in comparison with control (Figure 2B). The same concentration of Cd-EDTA leads to growth depression of the studied clones during cultivationlasting 12 days (Figures 2C,D). If we applied Pb-EDTA and/or Cd-EDTA (250 $\mu \mathrm{M})$, we observed marked growth depression at both 2/32 and PE 14 clones during cultivation (Figures 2A,B). The highest concentration of Pb-EDTA and/or Cd-EDTA $(500 \mu \mathrm{M})$ caused a decrease in growth of ESEs by about $20 \%$ in comparison with control. It follows from the results obtained that ESEs grew and developed better in the presence of $500 \mu \mathrm{M}$ of the metal ions than in the presence of $250 \mu \mathrm{M}$. This phenomenon probably relates to the increase of ESEs clusters area by intensive uptake of water from cultivation medium due to dilution of heavy metal concentration inside the cluster. 
We decided to evaluate our hypothesis by determining the content of water via protons by means of nuclear magnetic resonance (NMR). A colour scale showing both water and dry weight content in the ESEs was estimated (Figure 3). Then we utilized NMR to determine the water content of Cd-EDTA treated ESEs. We found out that water content in the ESEs increased with increasing concentration of cadmium(II) ions in the cultivation medium for the 14 day-long treatment (Figure 3). The increase was readily observable during the first three days of the treatment in comparison with control.

Figure 3. The influence of Cd-EDTA on water content in ESEs clone 2/32 treated by cadmium(II) ions. Concentration of ${ }^{1} \mathrm{H}$ measured by NMR corresponds with water content. For details see the Materials and Methods section.

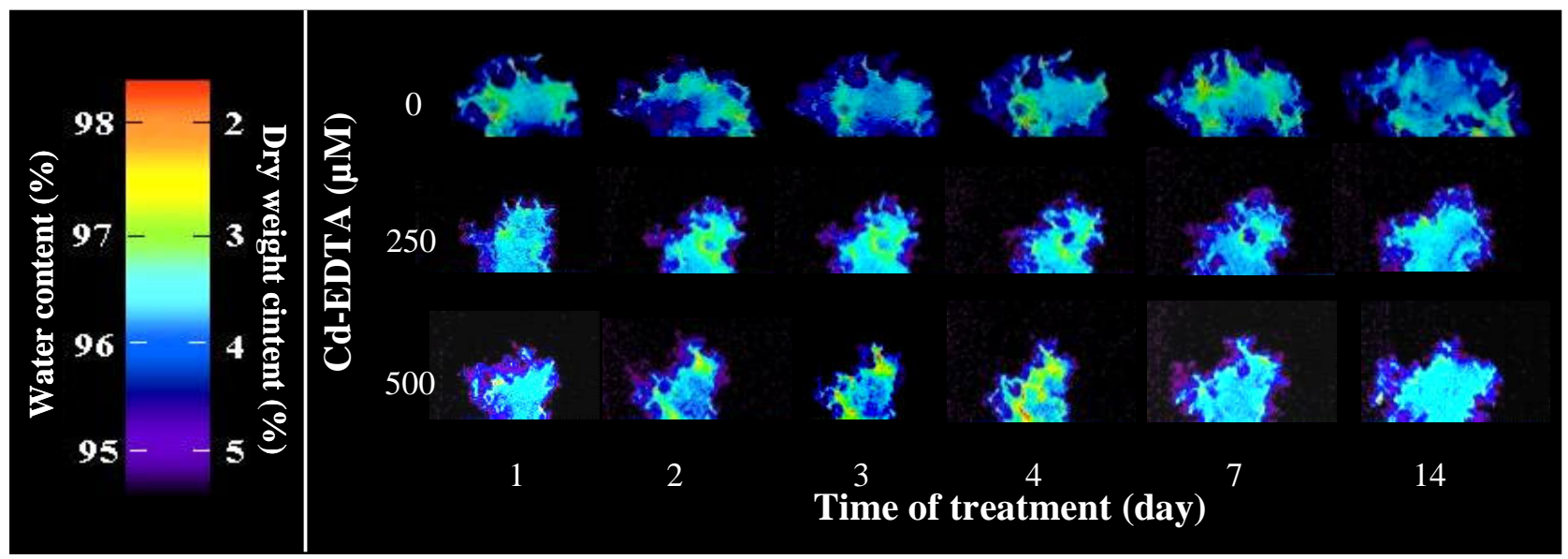

Because we estimated that the dry weight content decreased with increasing water content and vice versa, we compared these very surprising and interesting data with the determination of dry weight by drying of ESEs at $104{ }^{\circ} \mathrm{C}$ for $30 \mathrm{~min}$. We successfully confirmed that ESEs treated with the higher concentration of Cd-EDTA had less dry weight and contained more water. In the very end of the treatment, the dry weight content in ESEs was as followed: the control ESEs contained $4.74 \%$ of dry weight, ESEs treated with $50 \mu \mathrm{M}$ Cd-EDTA contained $4.08 \%$, ESEs treated with $250 \mu \mathrm{M}$ Cd-EDTA contained $3.34 \%$ and ESEs treated with $500 \mu \mathrm{M}$ Cd-EDTA contained $3.05 \%$. If we analysed the PbEDTA treated ESEs, we obtained similar results. In addition, we investigated the viability of ESEs using FDA/PI double staining coupled with IA [30]. The viability of non-treated clones 2/32 and PE 14 was $95-98 \%(n=10)$ at the beginning of the experiment and did not change during 12 day-long cultivation $( \pm 3 \%)$. Addition of Pb-EDTA and Cd-EDTA lead to a decrease in viability of ESEs (Figure 2). It is evident from the average tangents of the equation for Cd-EDTA (-)14.23 and for PbEDTA (-)6.95 that toxicity of Cd-EDTA is higher than toxicity of Pb-EDTA. This result was confirmed by the viability of ESEs treated by the highest concentrations of cadmium and lead ions (500 $\mu \mathrm{M}$ ), when viability of ESEs treated by cadmium was $20 \% \pm 7 \%$ and by lead $63 \% \pm 6 \%$ (Figure 2). The difference between viabilities was more than $40 \%$.

\subsection{Determination of activity of intracellular esterases}

Based on the previously published results it is assumable that the activity of intracellular esterases detected by using of fluorescein diacetate (Figure 4A) can be a suitable marker of cell metabolic 
activity $[31,32,38]$. In these recently published papers the biological samples have been disintegrated using a glassy homogenizer placed in an ice bath for $10 \mathrm{~min}$ prior to analysis of esterase activity [31,32]. This homogenization is rather laborious and time consuming. Thus, we were looking for another way of a sample homogenization, which would be more precise, easy to use and more rapid. For these purposes we attempted to use a hand-operated homogenizer ULTRA-TURRAX T8 for homogenizing of ESEs samples. We tested two revolutions per minute (10,000 and 25,000 rpm) and four homogenization times (1, 2, 3 and 5 minutes). We found out that activity of intracellular esterases increased with increasing rate of revolutions and time to homogenize. Due to low differences between 3 and 5 minutes, we choose 25,000 rpm and 3 minutes to homogenize as the most suitable conditions for preparation of the ESE samples. Moreover, the activity of certain number of ESE cells homogenized by ULTRA-TURRAX T8 under most suitable conditions was about $30 \%$ higher than the activity of the same number of ESE cells homogenized by the glassy homogenizer. Thus, ESE samples have been homogenized by ULTRA-TURRAX T8 in the following experiments.

Figure 4. Reaction scheme of fluorescein diacetate hydrolysis catalyzed by esterases (A). Influence of Pb-EDTA $(\mathrm{B}, \mathrm{C})$ and Cd-EDTA $(\mathrm{D}, \mathrm{E})$ on activity of intracellular esterases of early somatic spruce embryos, clones $2 / 32$ and PE 14 . The values represents mean $(\mathrm{n}=$ $3) \pm$ standard deviation. For other details see the Materials and Methods section.

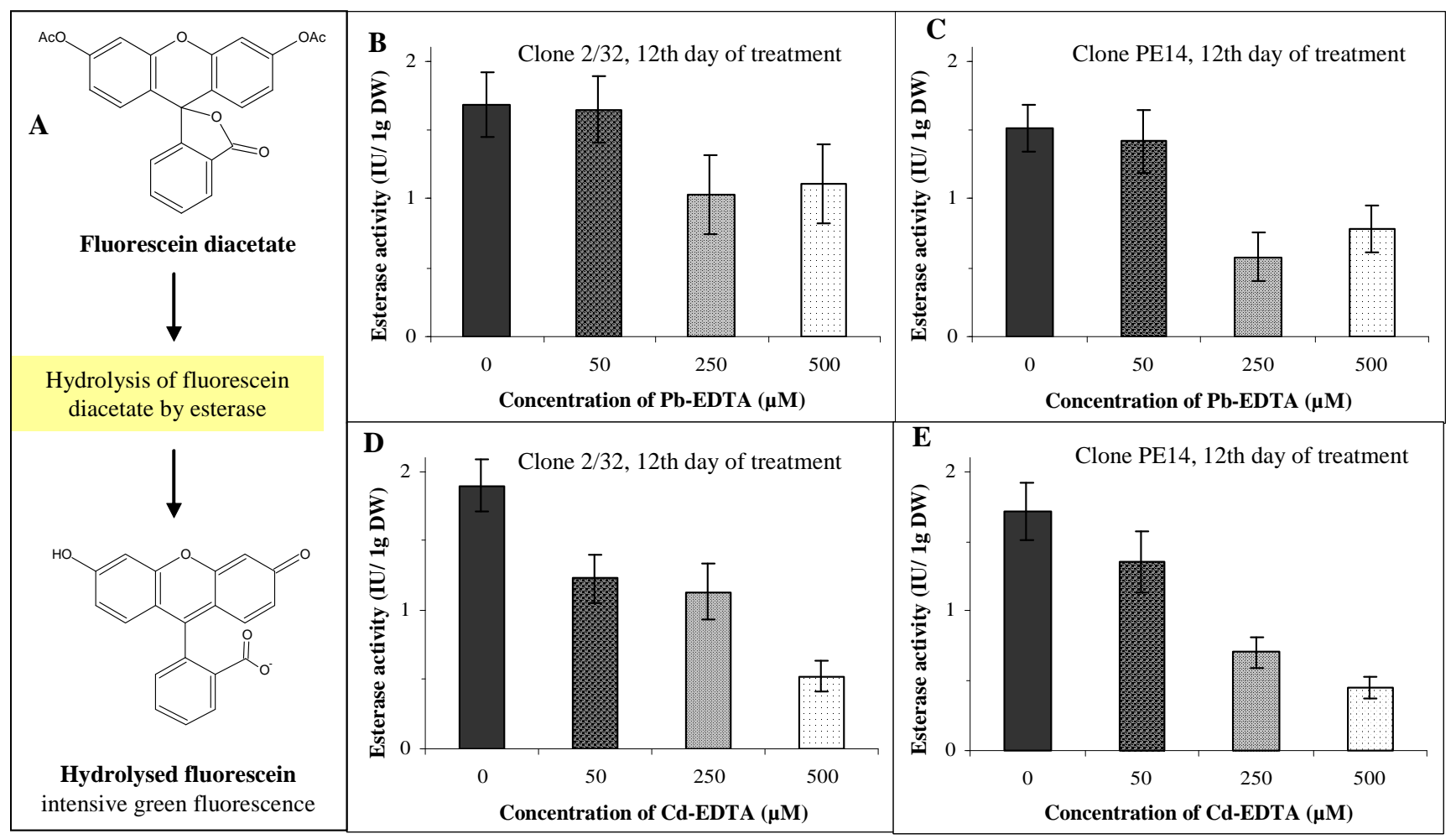

\subsection{Influence of heavy metals on the activity of intracellular esterases}

We found that the activity of intracellular esterases of the clones of interest decreased as the dose of both lead and cadmium ions increased (Figure 4). As for treatment with lead, the highest decrease in the activity of intracellular esterases was determined in ESEs of clone PE 14 exposed to a $250 \mu \mathrm{M}$ dose. This activity was two times lower in comparison with control ones. If we treated ESEs of clone 
PE 14 with the highest dose of lead ions $(500 \mu \mathrm{M})$, we found that the activity of intracellular esterases slightly increased (about $10 \%$ ), in comparison with the activity determined in clone treated with 250 $\mu \mathrm{M}$ of lead ions. The increase probably relates to the higher activity of detoxification mechanisms such as thiol synthesis. The activity of intracellular esterases of clone $2 / 32$ treated with 250 and $500 \mu \mathrm{M}$ of lead ions decreased about 61 and $65 \%$, respectively (Figures 4B,C). On the other hand, addition of CdEDTA ions to cultivation medium of ESEs clones of interest caused a decrease of the activity of intracellular esterases with increasing doses of the metal ions (Figures 4D,E). After treatment lasting 12 days, the activity of intracellular esterase of ESEs treated with the highest dose of Cd-EDTA (500 $\mu \mathrm{M}$ ) decreased up to $27 \%$ for clone $2 / 32$ and $26 \%$ for clone PE 14 in comparison with control ones.

\subsection{Electrochemical detection of glutathione - Use of the Brdicka reaction}

It is a common knowledge that plants can synthesize thiol compounds such as gluathione and phytochelatins if they are stressed by heavy metals [1,4,6]. Recently we were concerned with determination of glutathione and phytochelatins by different electrochemical techniques [15,17,47-51].

We found out that using of adsorptive stripping technique for accumulation of the studied thiol on the surface of mercury electrode is suitable for their very sensitive determination (Figure 5A). Particularly, we accumulated the studied thiol (glutathione) on the surface of the mercury working electrode, and then the electrode was washed. The washed electrode was consequently placed to electrochemical cell with supporting electrolyte, where electrochemical measurements proceeded (Figure 5A).

Primarily, we were working on the assumptions of a recently published paper, where GSH had been adsorbed on the surface of working electrode (HMDE) for $120 \mathrm{~s}$ [15]. Thus, we did the same and adsorbed GSH $(100 \mu \mathrm{M})$ gave five following signals Co1, $\mathrm{RS}_{2} \mathrm{Co}$, Cat1, Cat2 and Cat3. The labelling of signals is based on a number of papers published, which have been devoted to determination of thiols by the Brdicka reaction [16,17,39,52-63]. The signal called Co1 could result from reduction of $\left[\mathrm{Co}\left(\mathrm{H}_{2} \mathrm{O}\right)_{6}\right]^{2+}$ to $\mathrm{CoO}(\sim-1.0 \mathrm{~V})$. Another signal, which is appeared at the potential about $-1.0 \mathrm{~V}$, relates with the reduction of the RS2Co complex. The last three signals belongs to specific catalytic signals of peptides and proteins in the presence of cobalt solution Cat1 $(-1.2 \mathrm{~V})$; Cat2 $(-1.3 \mathrm{~V})$ and Cat3 $(-1.4 \mathrm{~V})[57,64]$. It clearly follows for the results that signal of $\mathrm{Co}^{2+}$ was shifted in the presence of glutathione to more positive potential. The observed changes relates with binding of $\mathrm{Co}^{3+}$ complex to structure of GSH - formation of RS2Co complex (Figure 5B).

The electrochemical behaviour of metallothionein measured by adsorptive transfer stripping technique in connection with different electrochemical methods is known [65-69], but the behaviour of such a small peptide as glutathione is not clear yet. As shown in Figure 5A and described by Vacek et al. [15], GSH can be adsorbed on the surface of HMDE, and the modified electrode is placed in an electrochemical cell, where electrochemical analysis proceeds. We investigated the influence of different GSH accumulation times on the surface of HMDE on the Cat3 signal (Figure 5C). The signals have been obtained within the range of durations of accumulation of $100-150 \mathrm{~s}$; thus, we used $120 \mathrm{~s}$ as previously for detection of GSH by AdTS DPV Brdicka reaction. Moreover, we found out that analysis of GSH at low temperatures (from 4 to $10^{\circ} \mathrm{C}$ ) is very effective with regards to the heights of signals. Particularly, the Cat3 signal increased about $100 \%$, if GSH has been measured at $4{ }^{\circ} \mathrm{C}$ in 
comparison with $27{ }^{\circ} \mathrm{C}$ (Figure 5D). This phenomenon can be associated with better stability of the supporting electrolyte containing ammonium buffer.

Figure 5. Scheme of adsorptive transfer stripping techniques in connection with differential pulse voltammetry - Brdicka reaction, HMDE - a hanging mercury drop electrode (working), $\mathrm{Ag} / \mathrm{AgCl}$ - reference electrode and $\mathrm{CE}$ - carbon electrode (auxiliary) (A).

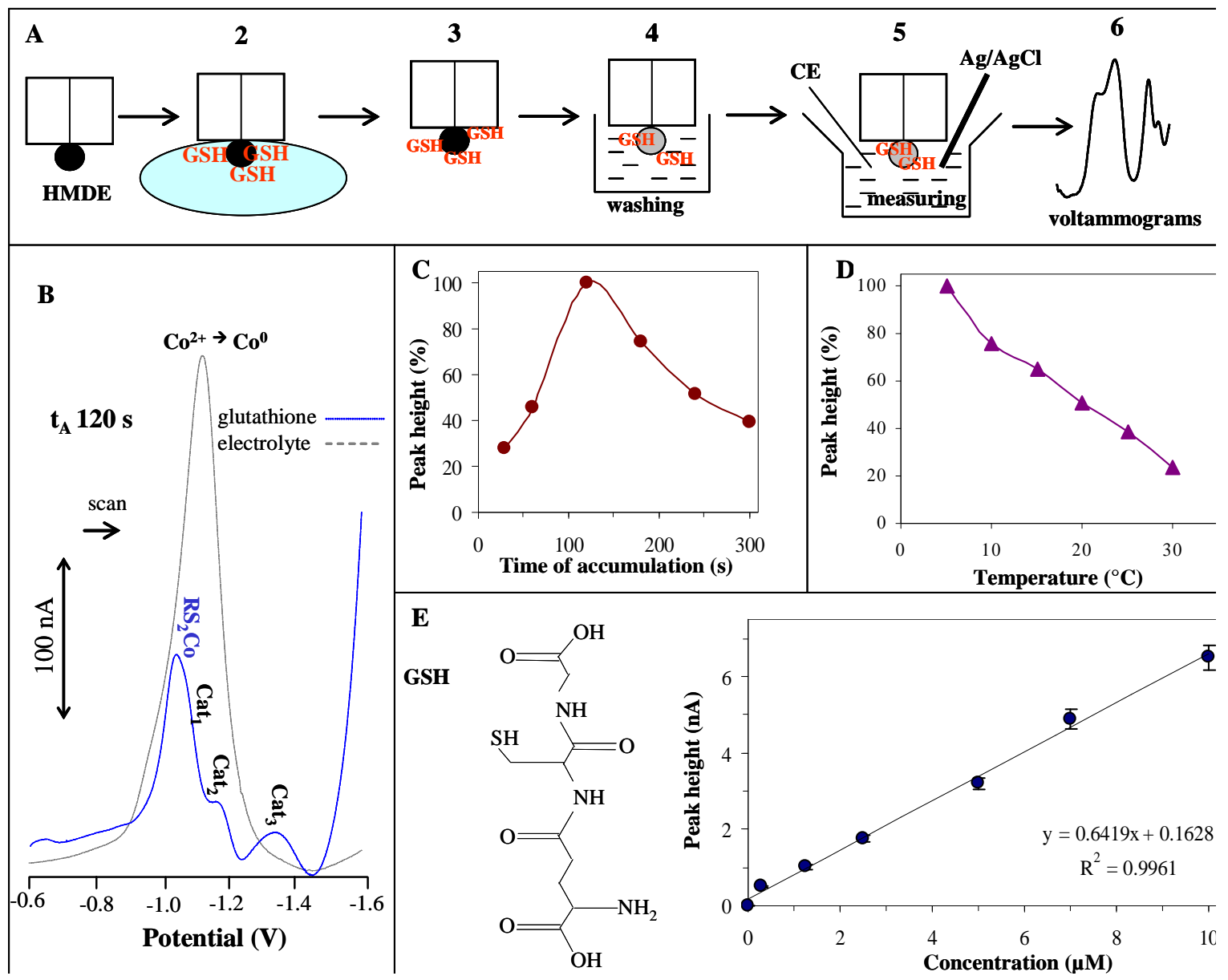

DP voltammogram of glutathione $(100 \mu \mathrm{M})$ measured in the presence of supporting electrolyte containing $1 \mathrm{mM} \mathrm{Co}\left(\mathrm{NH}_{3}\right)_{6} \mathrm{Cl}_{3}$ and $1 \mathrm{M}$ ammonia buffer $\left(\mathrm{NH}_{3}(\mathrm{aq})+\mathrm{NH}_{4} \mathrm{Cl}, \mathrm{pH}=9.6\right)$, time of accumulation $\mathrm{tA}=120 \mathrm{~s}$, temperature $27{ }^{\circ} \mathrm{C}(\mathrm{B})$. Dependences of Cat 3 peak height on time of accumulation (C); temperature (D) and GSH concentration $(0.3-10 \mu \mathrm{M})$. AdTS DPV Brdicka reaction parameters were as follows: an initial potential of $-0.6 \mathrm{~V}$, an end potential $-1.6 \mathrm{~V}$, a modulation time $0.057 \mathrm{~s}$, a time interval $0.2 \mathrm{~s}$, a step potential of $1.05 \mathrm{mV} / \mathrm{s}$, a modulation amplitude of $250 \mathrm{mV}$, Eads $=0 \mathrm{~V}$; time of accumulation $120 \mathrm{~s}$.

If we wanted to use the Brdicka reaction to analyze the ESEs samples, we had to choose a signal for quantification of GSH and measured calibration curve. For these purposes we used the Cat 3 signal (Figure 5B). The dependence of the signal height on glutathione concentration is shown in Figure 5E. The linear part of this dependence was observed in the concentration range of 0.3 to $10 \mu \mathrm{mol} / \mathrm{L}$ of GSH $\left(y=0.6419 x+0.1628 ; R^{2}=0.9961\right)$. After that, we analysed the ESEs sample by AdTS DPV Brdicka 
reaction. The typical DP voltammograms of ESEs treated by $250 \mu \mathrm{M}$ of Pb-EDTA and/or Cd-EDTA are shown in Figure 6A. The potential of the RS2Co signal of ESEs treated with Cd-EDTA was shifted to more positive potential (about $200 \mathrm{mV}$ ) in comparison with that ESEs treated with Pb-EDTA. The catalytic signals (Cat1 and Cat2) of ESEs treated by Cd-EDTA are better developed in comparison with the Pb-EDTA ones.

Figure 6. Typical DP voltammograms of ESEs treated by Cd-EDTA $(250 \mu \mathrm{M})$ and/or Pb-EDTA $(250 \mu \mathrm{M})$ after cultivation lasting four days. (A). Content of glutathione in ESEs clones 2/32 and PE 14 treated with Pb-EDTA (B, C) and Cd-EDTA (D, E). The values represents mean $(n=3) \pm$ standard deviation. For other details see the Materials and Methods section and Figure 4.

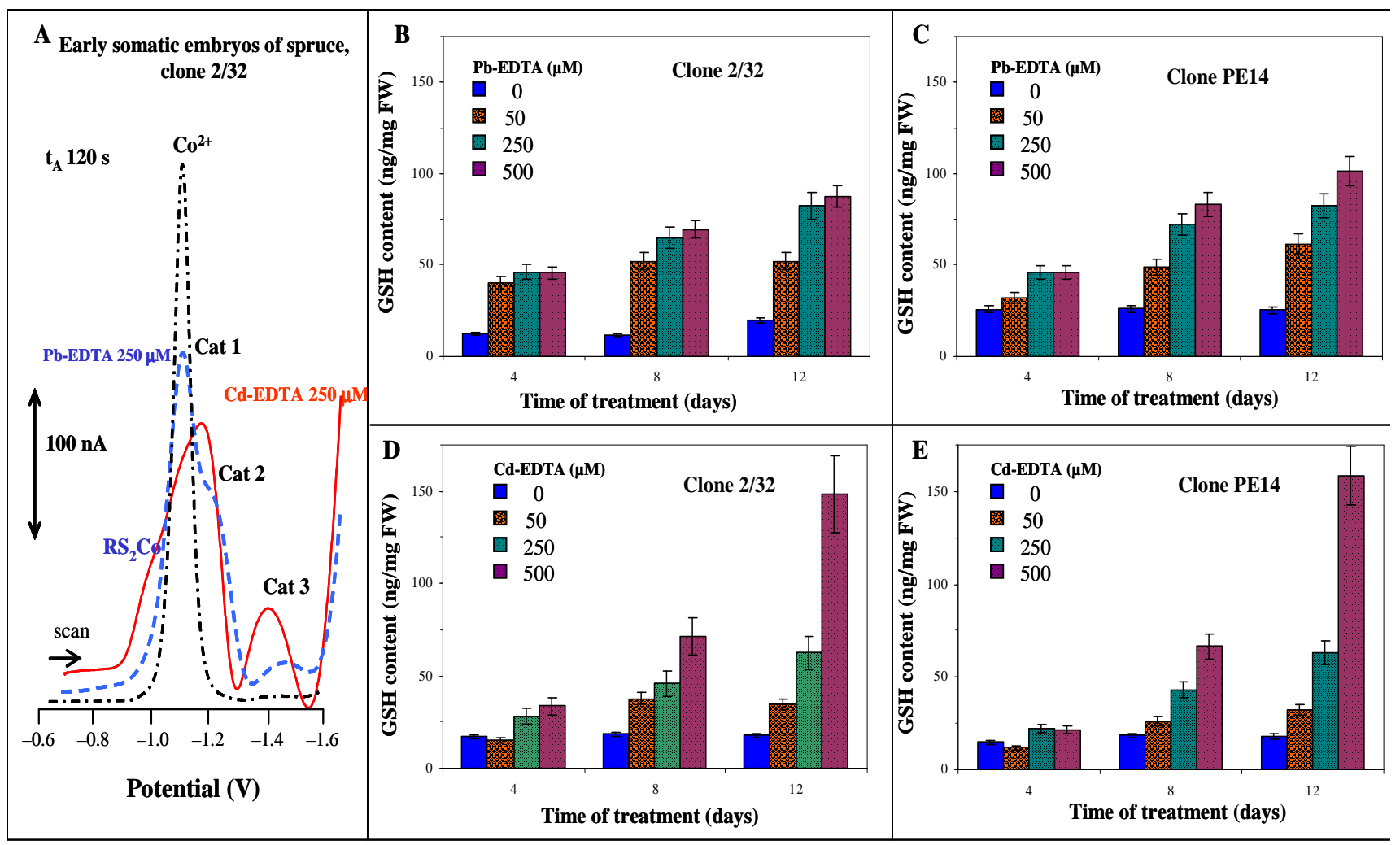

\subsection{Changes in content of glutathione in spruce embryos treated with heavy metals}

We found out that content of GSH markedly increased in ESEs treated with Pb-EDTA ions as early as after four days of treatment in comparison with control ones. After that, the GSH content increased more slightly. At the end of the experiment contents of GSH were as follows: control ESEs $-19.8 \pm$ $0.4 \mathrm{ng} / \mathrm{mg}$ (clone 2/32) and $25.4 \pm 1.1 \mathrm{ng} / \mathrm{mg}$ (clone PE 14), ESEs treated with $50 \mu \mathrm{M} \mathrm{Pb}-\mathrm{EDTA}-51.9$ $\pm 2.9 \mathrm{ng} / \mathrm{mg}$ (clone 2/32) and $61.3 \pm 3.3 \mathrm{ng} / \mathrm{mg}$ (clone PE 14), ESEs treated with $250 \mu \mathrm{M} \mathrm{Pb}-\mathrm{EDTA}-$ $82.2 \pm 3.9 \mathrm{ng} / \mathrm{mg}$ (clone 2/32) and $82.6 \pm 2.4 \mathrm{ng} / \mathrm{mg}$ (clone PE 14), ESEs treated with $500 \mu \mathrm{M} \mathrm{Pb}-$ EDTA $-87.5 \pm 2.5 \mathrm{ng} / \mathrm{mg}$ (clone 2/32) and $101 \pm 5 \mathrm{ng} / \mathrm{mg}$ (clone PE 14). It clearly follows from the results obtained that content of GSH was proportional to dose of Pb-EDTA and time of treatment (Figures 6B,C). A similar dependence was obtained for ESEs treated with Cd-EDTA. GSH content increased up to $148 \pm 6 \mathrm{ng} / \mathrm{mg}$ (clone 2/32) and $158 \pm 7 \mathrm{ng} / \mathrm{mg}$ (clone PE 14) after twelve day long 
treatment (Figures 6D,E), which is about 150 and $160 \%$ higher GSH content in comparison with ESEs treated with Pb-EDTA ions, respectively. The difference between GSH contents determined in ESEs treated with Pb-EDTA and Cd-EDTA ions relates with marked toxicity of cadmium ions, which is shown in growth curves, where the growth inhibition caused by cadmium ions is readily observable (Figure 2).

\section{Conclusions}

In the present work, we have shown that multi-instrumental analytical "point of view" could be used for solving of bio-analytical tasks. Particularly, image analysis, analysis of activity of intracellular esterases, nuclear magnetic resonance and adsorptive transfer stripping technique in connection with differential pulse voltammetry Brdicka reaction have been found to be very useful to investigate the effects on Spruce embryos of lead(II) and cadmium(II) ions.

\section{Acknowledgements}

This work was supported by grants of the Ministry of Education of Czech Republic (project MSMT 6215712402, 1M06030 and INCHEMBIOL 0021622412), Grant Agency of the Czech Republic (No. 522/07/0692) and IGA MZLU 2/2007. The authors are indebted to Dalibor Huska for excellent technical assistance.

\section{References}

1. Cobbett, C.S. Phytochelatin biosynthesis and function in heavy-metal detoxification. Curr. Opin. Plant Biol. 2000, 3, 211-216.

2. Ha, S.B.; Smith, A.P.; Howden, R.; Dietrich, W.M.; Bugg, S.; O'Connell, M.J.; Goldsbrough, P.B.; Cobbett, C.S. Phytochelatin synthase genes from arabidopsis and the yeast Schizosaccharomyces pombe. Plant Cell 1999, 11, 1153-1163.

3. Grill, E.; Winnacker, E.L.; Zenk, M.H. Phytochelatins - the Principal Heavy-Metal Complexing Peptides of Higher-Plants. Science 1985, 230, 674-676.

4. Meister, A.; Anderson, M.E. Glutathione. Annu. Rev. Biochem. 1983, 52, 711-760.

5. Leopold, I.; Gunther, D.; Schmidt, J.; Neumann, D. Phytochelatins and heavy metal tolerance. Phytochemistry 1999, 50, 1323-1328.

6. Grill, E.; Winnacker, E.-L.; Zenk, M.H. Phytochelatins: the principal heavy-metal complexing peptides of higher plants. Science 1985, 320, 674-676.

7. Cobbett, C.S.; Goldsbrough, P.B. Phytochelatins and metallothioneins: roles in heavy metal detoxification and homeostasis. Annu. Rev. Plant Biol. 2002, 53, 159-182.

8. Pacsial-Ong, E.J.; McCarley, R.L.; Wang, W.H.; Strongin, R.M. Electrochemical detection of glutathione using redox indicators. Anal. Chem. 2006, 78, 7577-7581.

9. Davoine, C.; Douki, T.; Iacazio, G.; Montillet, J.L.; Triantaphylides, C. Conjugation of keto fatty acids to glutathione in plant tissues. Characterization and quantification by HPLC-tandem mass spectrometry. Anal. Chem. 2005, 77, 7366-7372. 
10. Jin, W.R.; Li, X.J.; Gao, N. Simultaneous determination of tryptophan and glutathione in individual rat hepatocytes by capillary zone electrophoresis with electrochemical detection at a carbon fiber bundle-Au/Hg dual electrode. Anal. Chem. 2003, 75, 3859-3864.

11. Inoue, T.; Kirchhoff, J.R. Electrochemical detection of thiols with a coenzyme pyrroloquinoline quinone modified electrode. Anal. Chem. 2000, 72, 5755-5760.

12. Potesil, D.; Zelena, J.; Petrlova, J.; Adam, V.; Vacek, J.; Klejdus, B.; Zehnalek, J.; Trnkova, L.; Havel, L.; Kizek, R. Simultaneous femtomole determination of cysteine, reduced and oxidized glutathione, and phytochelatin in maize (Zea mays L.) kernels using high-performance liquid chromatography with electrochemical detection J. Chromatog. A 2005, 1084, 134-144.

13. Klejdus, B.; Zehnalek, J.; Adam, V.; Petrek, J.; Kizek, R.; Vacek, J.; Trnkova, L.; Roland, R.; Havel, L.; Kuban, V. Sub-picomolar HPLC/MS determination of glutathione in the maize (Zea mays L.) kernels exposed by cadmium. Anal. Chim. Acta 2004, 520, 117-124.

14. Petrlova, J.; Mikelova, R.; Stejskal, K.; Kleckerova, A.; Zitka, O.; Petrek, J.; Havel, L.; Zehnalek, J.; Adam, V.; Trnkova, L.; Kizek, R. Simultaneous determination of eight biologically active thiol compounds using gradient elution-liquid chromatography with Coul-Array detection. J. Sep. Sci. 2006, 29, 1166-1173.

15. Vacek, J.; Petrek, J.; Kizek, R.; Havel, L.; Klejdus, B.; Trnkova, L.; Jelen, F. Electrochemical determination of lead and glutathione in a plant cell culture. Bioelectrochemistry 2004, 63, 347351.

16. Fojta, M.; Fojtova, M.; Havran, L.; Pivonkova, H.; Dorcak, V.; Sestakova, I. Electrochemical monitoring of phytochelatin accumulation in Nicotiana tabacum cells exposed to sub-cytotoxic and cytotoxic levels of cadmium. Anal. Chim. Acta 2006, 558, 171-178.

17. Dorcak, V.; Sestakova, I. Electrochemical behavior of phytochelatins and related peptides at the hanging mercury drop electrode in the presence of cobalt(II) ions. Bioelectrochemistry 2006, 68, 14-21.

18. Yosypchuk, B.; Sestakova, I.; Novotny, L. Voltammetric determination of phytochelatins using copper solid amalgam electrode. Talanta 2003, 59, 1253-1258.

19. Kizek, R.; Vacek, J.; Trnkova, L.; Jelen, F. Cyclic voltammetric study of the redox system of glutathione using the disulfide bond reductant tris(2-carboxyethyl)phosphine. Bioelectrochemistry 2004, 63, 19-24.

20. Zitka, O.; Stejskal, K.; Kleckerova, A.; Adam, V.; Beklova, M.; Horna, A.; Supalkova, V.; Havel, L.; Kizek, R. Utilizing electrochemical techniques for detection of biological samples. Chem. Listy 2007, 101, 225-231.

21. Huska, D.; Zitka, O.; Adam, V.; Beklova, M.; Krizkova, S.; Zeman, L.; Horna, A.; Havel, L.; Zehnalek, J.; Kizek, R. A sensor for investigating the interaction between biologically important heavy metals and glutathione. Czech J. Anim. Sci. 2007, 52, 37-43.

22. Zehnalek, J.; Adam, V.; Kizek, R. Influence of heavy metals on production of protecting compounds in agriculture plants. Listy Cukrov. 2004, 120, 222-224.

23. Zehnalek, J.; Vacek, J.; Kizek, R. Application of higher plants in phytoremediation of heavy metals. Listy Cukrov. 2004, 120, 220-221. 
24. Supalkova, V.; Huska, D.; Diopan, V.; Hanustiak, P.; Zitka, O.; Stejskal, K.; Baloun, J.; Pikula, J.; Havel, L.; Zehnalek, J.; Adam, V.; Trnkova, L.; Beklova, M.; Kizek, R. Electroanalysis of plant thiols. Sensors 2007, 7, in press.

25. Mohr, H.; Schopfer, P. Plant Physiology, Springer: ? 1995; p. 629.

26. Hader, D.P. Image analysis in biology, CRC Press: London, 1992.

27. Ibaraki, Y.; Kenji, K. Application of image analysis to plant cell suspension cultures. Comput. Electron. Agric. 2001, 30, 193-203.

28. Olofsdotter, M. Image processing: a non-destructive method for measuring growth in cell and tissue culture. Plant Cell Reports 1993, 12, 216-219.

29. Gagna, C.E.; Winokur, D.; Larnbert, W.C. Cell biology, chemogenomics and chemoproteomics. Cell Biol. Int. 2004, 28, 755-764.

30. Petrek, J.; Vitecek, J.; Vlasinova, H.; Kizek, R.; Kramer, K.J.; Adam, V.; Klejdus, B.; Havel, L. Application of computer imaging, stripping voltammetry and mass spectrometry to study the effect of lead (Pb-EDTA) on the growth and viability of early somatic embryos of Norway spruce (Picea abies/L./Karst.). Anal. Bioanal. Chem. 2005, 383, 576-586.

31. Vitecek, J.; Adam, V.; Petrek, J.; Vacek, J.; Kizek, R.; Havel, L. Esterases as a marker for growth of BY-2 tobacco cells and early somatic embryos of the Norway spruce. Plant Cell Tissue Organ Cult. 2004, 79, 195-201.

32. Vitecek, J.; Adam, V.; Petrek, J.; Babula, P.; Novotna, P.; Kizek, R.; Havel, L. Application of fluorimetric determination of esterases in plant material. Chem. Listy 2005, 99, 496-501.

33. Vitecek, J.; Petrlova, J.; Petrek, J.; Adam, V.; Havel, L.; Kramer, K.J.; Kizek, R. Application of fluorimetric analysis of plant esterases to study of programmed cell death and effects of cadmium(II) ions. Biol. Plant. 2007, 51, 551-555.

34. Vitecek, J.; Wunschova, A.; Petrek, J.; Adam, V.; Kizek, R.; Havel, L. Cell death induced by sodium nitroprusside and hydrogen peroxide in tobacco BY 2 cell suspension. Biol. Plant. 2007, 51, 472-479.

35. von Arnold, S.J. Improved efficiency of somatic embryogenesis in mature embryos of Picea abies (L.). Plant Phys. 1987, 128, 233-244.

36. Havel, L.; Durzan, D.J. Apoptosis during diploid parthenogenesis and early somatic embryogenesis of Norway spruce. Int. J. Plant Sci. 1996, 157, 8-16.

37. Vlasinova, H.; Mikulecky, M.; Havel, L. The mitotic activity of Norway spruce polyembryonic culture oscillates during the synodic lunar cycle. Biol. Plant. 2003, 47, 475-476.

38. Vitecek, J.; Petrlova, J.; Adam, V.; Havel, L.; Kramer, K.J.; Babula, P.; Kizek, R. A fluorimetric sensor for detection of one living cell. Sensors 2007, 7, 222-238.

39. Petrlova, J.; Potesil, D.; Mikelova, R.; Blastik, O.; Adam, V.; Trnkova, L.; Jelen, F.; Prusa, R.; Kukacka, J.; Kizek, R. Attomole voltammetric determination of metallothionein. Electrochim. Acta 2006, 51, 5112-5119.

40. Bartusek, K.; Dokoupil, Z.; Gescheidtova, E. Magnetic field mapping around metal implants using an asymmetric spin-echo MRI sequence. Meas. Sci. Technol. 2006, 17, 3293-3300.

41. Bartusek, K.; Gescheidtova, E. Testing the quality of magnetic gradient fields for studying selfdiffusion processes by magnetic resonance methods. Meas. Sci. Technol. 2006, 17, 2256-2262. 
42. Bartusek, K. Processing of MR images weighted by relaxation time T-2 to increase their contrast resolution. Meas. Sci. Technol. 2006, 17, 727-730.

43. Bartusek, K.; Gescheidtova, E. MR measurement technique of rapidly switched gradient magnetic fields in MR tomography. Appl. Magn. Reson. 2005, 29, 675-686.

44. Mojica, E.R.E.; Gomez, S.P.; Micor, J.R.L.; Deocaris, C.C. Lead detection using a pineapple bioelectrode. Philipp. Agric. Sci. 2006, 89, 134-140.

45. Vassil, A.D.; Kapulnik, Y.; Raskin, I.; Salt, D.E. The Role of EDTA in Lead Transport and Accumulation by Indian Mustard. Plant Phys. 1998, 117, 447-453.

46. Meagher, R.B. Phytoremediation of toxic elemental and organic pollutants. Curr. Opin. Plant Biol. 2000, 3, 153-162.

47. Cruz, B.H.; Diaz-Cruz, J.M.; Arino, C.; Esteban, M. Complexation of heavy metals by phytochelatins: Voltammetric study of the binding of $\mathrm{Cd} 2+$ and $\mathrm{Zn} 2+$ ions by the phytochelatin (gamma-Glu-Cys)(3)Gly assisted by multivariate curve resolution. Environ. Sci. Technol. 2005, 39, 778-786.

48. Cruz, B.H.; Diaz-Cruz, J.M.; Sestakova, I.; Velek, J.; Arino, C.; Esteban, M. Differential pulse voltammetric study of the complexation of $\mathrm{Cd}(\mathrm{II})$ by the phytochelatin (gamma-Glu-Cys)(2)Gly assisted by multivariate curve resolution. J. Electroanal. Chem. 2002, 520, 111-118.

49. Sestakova, I.; Vodickova, H.; Mader, P. Voltammetric methods for speciation of plant metallothioneins. Electroanalysis 1998, 10, 764-770.

50. Vodickova, H.; Pacakova, V.; Sestakova, I.; Mader, P. Analytical methods for determination of metallothioneins. Chem. Listy 2001, 95, 477-483.

51. Dabrio, M.; Rodriguez, A.R.; Bordin, G.; Bebianno, M.J.; De Ley, M.; Sestakova, I.; Vasak, M.; Nordberg, M. Recent developments in quantification methods for metallothionein. J. Inorg. Biochem. 2002, 88, 123-134.

52. Dragun, Z.; Raspor, B.; Erk, M.; Ivankovic, D.; Pavicic, J. The influence of the biometric parameters on metallothionein and metal level in the heat-treated cytosol of the whole soft tissue of transplanted mussels. Environ. Monit. Assess. 2006, 114, 49-64.

53. Ivankovic, D.; Pavicic, J.; Erk, M.; Filipovic-Marijic, V.; Raspor, B. Evaluation of the Mytilus galloprovincialis Lam. digestive gland metallothionein as a biomarker in a long-term field study: Seasonal and spatial variability. Mar. Pollut. Bull. 2005, 50, 1303-1313.

54. Raspor, B.; Dragun, Z.; Erk, M.; Ivankovic, D.; Pavicic, J. Is the digestive gland of Mytilus galloprovincialis a tissue of choice for estimating cadmium exposure by means of metallothioneins? Sci. Total Environ. 2004, 333, 99-108.

55. Dragun, Z.; Erk, M.; Raspor, B.; Ivankovic, D.; Pavicic, J. Metal and metallothionein level in the heat-treated cytosol of gills of transplanted mussels Mytilus galloprovincialis Lmk. Environ. Int. 2004, 30, 1019-1025.

56. Filipovic, V.; Raspor, B. Metallothionein and metal levels in cytosol of liver, kidney and brain in relation to growth parameters of Mullus surmuletus and Liza aurata from the Eastern Adriatic Sea. Water Res. 2003, 37, 3253-3262.

57. Erk, M.; Ivankovic, D.; Raspor, B.; Pavicic, J. Evaluation of different purification procedures for the electrochemical quantification of mussel metallothioneins. Talanta 2002, 57, 1211-1218. 
58. Raspor, B.; Paic, M.; Erk, M. Analysis of metallothioneins by the modified Brdicka procedure. Talanta 2001, 55, 109-115.

59. Erk, M.; Raspor, B. Interference of $\mathrm{Pb}$ leaching from the $\mathrm{pH}$ electrode on $\mathrm{Cd}$-metallothionein complex. Anal. Chim. Acta 2001, 442, 165-170.

60. Raspor, B. Elucidation of the mechanism of the Brdicka reaction. J. Electroanal. Chem. 2001, 503, 159-162.

61. Erk, M.; Raspor, B. Advantages and disadvantages of voltammetric method in studying cadmiummetallothionein interactions. Cell. Mol. Biol. 2000, 46, 269-281.

62. Raspor, B.; Pavicic, J. Electrochemical methods for quantification and characterization of metallothioneins induced in Mytilus galloprovincialis. Fresenius J. Anal. Chem. 1996, 354, 529534.

63. Selesovska-Fadrna, R.; Fojta, M.; Navratil, T.; Chylkova, J. Brdicka-type processes of cysteine and cysteine-containing peptides on silver amalgam electrodes. Anal. Chim. Acta 2007, 582, 344352.

64. Kizek, R.; Vacek, J.; Trnkova, L.; Klejdus, B.; Havel, L. Application of catalytic reactions on a mercury electorode for metallothionein electrochemical detection. Chem. Listy 2004, 98, 166-173.

65. Adam, V.; Petrlova, J.; Potesil, D.; Zehnalek, J.; Sures, B.; Trnkova, L.; Jelen, F.; Kizek, R. Study of metallothionein modified electrode surface behavior in the presence of heavy metal ionsbiosensor. Electroanalysis 2005, 17, 1649-1657.

66. Krizkova, S.; Adam, V.; Petrlova, J.; Zitka, O.; Stejskal, K.; Zehnalek, J.; Sures, B.; Trnkova, L.; Beklova, M.; Kizek, R. A suggestion of electrochemical biosensor for study of platinum(II)-DNA interactions. Electroanalysis 2007, 19, 331-338.

67. Adam, V.; Krizkova, S.; Zitka, O.; Trnkova, L.; Petrlova, J.; Beklova, M.; Kizek, R. Determination of apo-metallothionein using adsorptive transfer stripping technique in connection with differential pulse voltammetry. Electroanalysis 2007, 19, 339-347.

68. Petrlova, J.; Potesil, D.; Zehnalek, J.; Sures, B.; Adam, V.; Trnkova, L.; Kizek, R. Cisplatin electrochemical biosensor. Electrochim. Acta 2006, 51, 5169-5173.

69. Kukacka, J.; Krizkova, S.; Zitka, O.; Prusa, R.; Adam, V.; Sures, B.; Beklova, M.; Kizek, R. Study of nucleic acids interactions with platinum based cytostatics using biosensor. FASEB J. 2007, 21, A262-A262.

(C) 2007 by MDPI (http://www.mdpi.org). Reproduction is permitted for noncommercial purposes. 